\title{
Sistema de gestão para biblioteca universitária (SGBU) ${ }^{1}$
}

\author{
Management system for university library (SGBU)
}

Cibele Vasconcelos DZIEKANIAK²

\section{RESUMO}

Baseando-se na importância da Biblioteca Universitária para o processo educacional, e tendo a sua excelência administrativa como um dos pressupostos para atender satisfatoriamente às necessidades dos usuários, a autora pretende fornecer subsídios que auxiliem na gestão de Bibliotecas Universitárias, por meio de uma proposta metodológica denominada Sistema de Gestão para Biblioteca Universitária (SGBU). Paralelamente ao desenvolvimento do SGBU, foram conduzidas as implementações em uma Biblioteca Universitária (estudo de caso) com o intuito de validar o modelo de Sistema de Gestão proposto, bem como testar a sua real aplicabilidade. No conjunto de benefícios gerados pelo estudo, está a contribuição para com os bibliotecários administradores, devido ao seu caráter didático, já que se trata de um Sistema de Gestão específico para Bibliotecas Universitárias, o que transpõe a mera aplicação de um sistema pronto, que não preencha a real necessidade de uma Biblioteca Universitária. Conclui-se, portanto, que um Sistema de Gestão para Biblioteca Universitária que compreenda questões institucionais, gerenciais, operacionais, organizacionais, humano-comportamentais e ambientais constitui-se em um efetivo instrumento de suporte à ação administrativa do profissional bibliotecário.

Palavras-chave: Biblioteconomia; biblioteca universitária; administração de biblioteca universitária; sistema de gestão; meio ambiente.

\begin{abstract}
Focused on the importance of University Library for the educational process, and having its administrative excellence as one of the requisites to answer satisfactorily the users' necessities, the author intends to provide subsidies to help University Libraries management by pointing a methodological proposition named Management System for University Library (SGBU). Along with the development of SGBU, the implementations were conducted in a University Library (study of case) with the objective to validate the Management System model proposed, as well as to test its real applicability. In the universe of benefits generated by the study, it shows out the contribution for librarian-managers, due to its didactic characteristic, once it is a specific Management System for University Libraries and overpasses the simple application of a done system which doesn't fit to its real necessity. It leads out to the conclusion that a Management System for University Library, which has institutional, management, operational, organizational, human-behavioral and environmental questions, constitutes itself in an effective support instrument to the administrative action of the librarian.
\end{abstract}

Keywords: Librarianship; university library; university Library administration; management system; environment.

1 presente artigo corresponde, resumidamente, à proposta metodológica denominada Sistema de Gestão para Biblioteca Universitária (SGBU), apresentada pela autora em sua dissertação de mestrado, defendida no Programa de Pós-Graduação em Engenharia de Produção. Área de Qualidade e Produtividade, da Universidade Federal de Santa Maria (UFSM, RS). Publicado na revista internacional Biblios (Lima-Peru), n.31, 2008. Disponível em: <http://www.revistabiblios.com/ojs/index.php/biblios/article/viewFile/ $36 / 50>$.

${ }^{2}$ Mestre em Engenharia de Produção, Universidade Federal de Santa Maria - UFSM. Diretora da Biblioteca da Faculdade de Direito de Santa Maria - FADISMA. Rua Duque de Caxias, 2319, Nossa Senhora Medianeira, 97060-210, Santa Maia, RS. E-mail: <cibelevasconcelos@gmail.com>.

Recebido em 13/3/2008 e aceito para publicação em 8/8/2008. 


\section{INTRODUÇÃO}

Aprender a conhecer, aprender a fazer, aprender a viver juntos e aprender a ser. Estes são os quatro pilares da educação, definidos pela Comissão Internacional sobre Educação para o Século XXI, coordenada por Delors et al. (1999) e que, de acordo com a UNESCO, precisam ser fortalecidos.

Nesse sentido, não se concebe mais a educação apenas transmitir conhecimentos, mas sim, fornecer subsídios para que cada indivíduo construa suas idéias e descubra/desenvolva seu potencial. Diante desse cenário, cabe à biblioteca assumir e desempenhar seu papel de ator principal no processo educacional, e para que isso ocorra, uma adequada estrutura é condição necessária, e isso envolve uma série de requisitos básicos, tais como recursos humanos, materiais, financeiros e tecnológicos apropriados, além de uma administração capacitada, exercida por meio de um profissional bibliotecário. Caso contrário, a biblioteca passa a atuar apenas como ator coadjuvante, assumindo papel secundário e, por conseguinte, distanciando-se da sua verdadeira missão e responsabilidade no sistema educativo.

No âmbito da educação superior, compete à Biblioteca Universitária (BU) assumir esse papel, por ser um importante instrumento de que a universidade dispõe para exercer sua função social e de cidadania e oferecer uma formação global. A evolução do ensino, da pesquisa e da extensão nas universidades brasileiras tem contribuído para o desenvolvimento do país em todos os níveis (tecnológico, social, econômico, cultural e ambiental) e, sendo assim, crescem as exigências para o desenvolvimento, aperfeiçoamento, melhoria contínua e responsabilidade social ${ }^{3}$ das Bibliotecas Universitárias.

Todavia, para que a BU cumpra sua função e responsabilidade com excelência necessita, sobretudo, de uma administração eficaz. Nesse sentido, a administração da Biblioteca Universitária tornou-se um dos pontos-chave para a qualidade da educação e para a obtenção de um bom desempenho e sucesso, tanto da própria biblioteca, como da Instituição e Ensino Superior (IES) na qual se encontra inserida. Com isso, exigem-se dos bibliotecários administradores não apenas conhecimento na área de Biblioteconomia e habilidades gerenciais, mas também conhecimentos aprofundados na área de Administração, ou seja, domínio dos processos, das funções administrativas e financeiras, das teorias, dos instrumentos e tecnologias de gestão, entre outros.

Ainda que a Administração esteja sendo abordada e discutida com maior ênfase no âmbito biblioteconômico e tenha conquistado cada vez mais a atenção dos estudiosos, assim como mais espaço nas estruturas curriculares dos cursos de Biblioteconomia, necessita ser mais bem explorada. Para que sejam proporcionados maiores subsídios aos profissionais bibliotecários, torna-se cada vez mais importante o desenvolvimento de pesquisas teóricas e práticas a respeito de administração de bibliotecas, pois, além de haver um número reduzido de bibliografias pertinentes a esta temática, algumas já se tornaram obsoletas.

Essa comprovação deu-se por meio de uma pesquisa realizada pela autora nos ementários dos Cursos de Biblioteconomia, no ano de $2003^{4}$, em que a grande maioria dos cursos ainda utilizava bibliografias específicas de administração de bibliotecas da década de 70 e 80, e talvez isso tenha ocorrido pelo fato de a produção científica na área ser escassa, não acompanhando a evolução tecnológica e as necessidades acadêmicas.

Para elucidar tal afirmativa, segundo Passos (2005), de acordo com informações da Câmara Brasileira do Livro (CBL), no ano de 2002 foram publicados em papel, na área de Biblioteconomia, 15 títulos em primeira edição e 10 títulos reeditados; já na área de Direito foram publicados 920 títulos em primeira edição e 1250 títulos reeditados; em Administração, 280 títulos em primeira edição e 610 títulos reeditados. Embora não tenha sido disponibilizado pela CBL o total de publicações atuais por áreas do conhecimento, percebe-se, pela estatística do ano de 2002, que a

\footnotetext{
3 Essa responsabilidade social perpassa a questão ambiental, inclusive. A compreensão, conscientização e a própria ação em prol do meio ambiente dependem efetivamente da concentração de esforços no meio acadêmico, e, por ser a Biblioteca Universitária um instrumento de apoio à Instituição de Ensino Superior, pode ser considerada como um dos meios para se atingir o saber e a sensibilização ambiental da comunidade acadêmica.

4 A referida pesquisa foi publicada na revista Informação e Sociedade: estudos, João Pessoa, v. 13, n. 2., jul./dez. 2003, intitulada "A inserção de teorias e práticas administrativas nos currículos dos Cursos de Biblioteconomia".
} 
oferta de livros impressos publicados na área de Biblioteconomia foi limitada, principalmente se compararmos com a quantidade de publicações das demais áreas. Sendo assim, a publicação de obras sobre um tema tão específico como Administração de Bibliotecas Universitárias é ainda menor.

O avanço sistemático de novas tecnologias, - crescimento informacional nos mais variados suportes (impresso, digital, eletrônico) e a responsabilidade social que permeia as Bibliotecas Universitárias demandam uma postura proativa por parte do bibliotecário administrador, isto é, ter clareza de "onde se quer chegar e como se quer chegar", incluindo a visão do meio instável em que atua. Para isso, torna-se imprescindível o conhecimento e a fundamentação teórico-prática no campo da administração de Bibliotecas.

Baseando-se na importância que a BU tem para a comunidade acadêmica e para a sociedade em geral, e tendo a excelência administrativa como um dos pressupostos para atender satisfatoriamente às necessidades dos usuários, a autora pretende fornecer subsídios que auxiliem na gestão de Bibliotecas Universitárias, por meio de uma proposta metodológica denominada Sistema de Gestão para Biblioteca Universitária (SGBU).

O SGBU foi desenvolvido baseando-se nas técnicas e conceitos dos principais autores da literatura temática tais como Arantes, Chiavenato, Davenport, Drucker, Faria, Freeman, Kwasnicka, Masiero, Maximiano, Megginson, Meira, Mendonça, Mosley, Oliveira, Pietri Jr., Stoner, e Valadares ${ }^{5}$, bem como nos Critérios de Excelência da Fundação Nacional da Qualidade (FNQ), uma vez que, utilizando-os como referência, as organizações podem realizar uma autoavaliação e obter um diagnóstico exato da sua gestão organizacional. Os Critérios de Excelência da (FNQ) são úteis para a avaliação, diagnóstico e desenvolvimento do sistema de gestão de qualquer tipo de organização, uma vez que são flexíveis, possuem uma linguagem simples e não prescrevem ferramentas e práticas de gestão específicas (Fundação..., 2002).

A estrutura do SGBU foi baseada no Sistema de Gestão Empresarial proposto por Arantes (1998, p.18), por ser entendido como "uma base conceitual, suportada por experiências práticas, que serve como orientação para a concepção de Sistemas de Gestão adequados às peculiaridades técnicas e culturais de cada situação".

A proposta de trabalho foi, portanto, estruturar um Sistema de Gestão específico para Biblioteca Universitária, com o intuito de ser um efetivo instrumento de suporte à ação administrativa do profissional bibliotecário. Entretanto tinha-se como problema de pesquisa o "como estruturá-lo?". A pesquisa foi realizada baseando-se na hipótese de que um Sistema de Gestão para Biblioteca Universitária, que compreenda questões institucionais, gerenciais, operacionais, organizacionais, humano-comportamentais e ambientais constitui-se em um efetivo instrumento de suporte à ação administrativa do profissional bibliotecário.

Para validar o sistema proposto, foi selecionada uma Biblioteca Universitária de porte médio para implementar o SGBU. A BU escolhida facilitou consideravelmente a implementação do Sistema de Gestão desenvolvido pelo conhecimento que a autora detinha dos seus processos, produtos e serviços; pela facilidade de acesso às informações e aos colaboradores; pela autonomia na tomada de decisão; e pelo fato de a biblioteca estar diretamente ligada à Reitoria, o que proporcionou uma comunicação rápida, e evitou distorções.

Outro fator contribuinte para o sucesso do desenvolvimento e implantação do SGBU foi a metodologia utilizada, porque permitiu ampla liberdade na coleta, análise e complementação dos dados, quando necessário, facilidade que uma pesquisa quantitativa não permitiria, bem como admitiv a efetiva participação dos colaboradores da BU em questão.

O conjunto de procedimentos metodológicos utilizados no presente estudo foi: - quanto aos objetivos: caráter exploratório; - quanto à abordagem: qualitativa, e, nesse sentido, foram utilizados instrumentos alternativos na coleta de dados (entrevista nãoestruturada, observação assistemática, observação participante natural, anotações de campo de natureza reflexiva e análise de documentos internos); - quanto

\footnotetext{
5 Os autores e suas respectivas obras estão referenciados na dissertação da autora, uma vez que o presente artigo corresponde, resumidamente, à proposta metodológica apresentada em sua dissertação de mestrado intitulada Sistema de Gestão para Biblioteca Universitária (SGBU), defendida no Programa de Pós-Graduação em Engenharia de Produção. Área de Qualidade e Produtividade, da Universidade Federal de Santa Maria (UFSM, RS).
} 
aos procedimentos técnicos: a pesquisa bibliográfica, a pesquisa documental e o estudo de caso; - população da pesquisa: direção da Instituição de Ensino Superior, bibliotecários e funcionários da Biblioteca Universitária, bem como seus diversos tipos de usuários (docentes, discentes, funcionários, egressos e comunidade em geral).

No conjunto de benefícios gerados pelo presente trabalho está a contribuição para com os bibliotecários administradores, devido ao seu caráter didático, já que se trata de um Sistema de Gestão específico para BU, o que transpõe a mera aplicação de um sistema pronto, que não preencha a real necessidade de uma BU, podendo constituir-se num efetivo instrumento de suporte à administração de Bibliotecas Universitárias.

Acredita-se que o enfoque dado por este estudo ao aspecto administrativo de Bibliotecas Universitárias proporcione maior fundamentação no construto teóricoprático da área, além de minimizar as dificuldades enfrentadas pelos bibliotecários administradores, problemas que, de certa forma, acabam comprometendo a eficiência, qualidade, produtividade e responsabilidade social das Bibliotecas Universitárias e, conseqüentemente, a própria educação de um modo geral.

\section{SISTEMA DE GESTÃO: INSTRUMENTO FACILITADOR E DE SUPORTE À AÇÃO ADMINIS- TRATIVA}

A tarefa empresarial realizada pela administração constitui-se em um conjunto de atividades interrelacionadas, tendo como função atingir os resultados preestabelecidos e atender às expectativas organizacionais. Para cumprir e facilitar seu papel, a administração utilizase de vários instrumentos de gestão.

\begin{abstract}
Estes instrumentos são compostos por conceitos e técnicas que vêm sendo criados, aplicados e aprimorados ao longo da história da Administração e cobrem todas as necessidades da tarefa empresarial. [...]. Eles auxiliam a administração também em seus esforços de definir os procedimentos e os métodos para a execução das atividades, a fixar e compartilhar os papéis e as responsabilidades entre a equipe, a promover as relações e o entendimento comum. (Arantes, 1998, p.86).
\end{abstract}

Destarte, os instrumentos de gestão podem ser considerados os meios pelos quais a administração alcança os objetivos empresariais e atinge resultados efetivos. A integração desses instrumentos, bem como a inter-relação existente entre eles compõem um Sistema de Gestão Empresarial. Compete ao administrador a responsabilidade pelo desenvolvimento do Sistema de Gestão, isto é, cabe a ele participar e contribuir ativa e diretamente na sua concepção, encarando-o sempre como sendo de sua responsabilidade.

No campo de Administração de Empresas a denominação Sistemas de Gestão Empresarial (SGE) ou Enterprise Systems (ESs), conhecido igualmente por Sistemas Integrados de Gestão (SIG) ou Enterprise Resource Planning (ERP), também tem sido empregada para conceituar as ferramentas de informática apropriadas à gestão empresarial. Nesse contexto, Davenport (2002, p. 18) define Sistemas de Gestão Empresarial como:

[...] pacotes de aplicativos de computador que dão suporte à maioria das necessidades de informação de uma empresa (ou organização não-lucrativa, universidade ou agência governamental). [...] Além de aplicativos para a produtividade pessoal tais como planilhas eletrônicas e processadores de textos em computadores pessoais, de sistemas de produção altamente especializados como controle de processos, e de sistemas para acesso à informação e ao conhecimento baseados na internet, o SGE pode constituir o único sistema de informação de negócios indispensável a uma empresa.

O conceito de Sistema de Gestão referido neste estudo nada tem a ver com pacotes de aplicativos de computador e softwares de gestão, e sim, o conjunto de instrumentos de gestão, vistos de maneira integrada, os quais oferecem suporte à ação da administração.

\section{UMA PROPOSTA METODOLÓGICA PARA GESTÃO DE BIBLIOTECAS UNIVERSITÁRIAS}

Decidir sobre um Sistema de Gestão para Biblioteca Universitária exige reflexão a respeito da razão de ser de uma BU, isto é, qual o seu papel e contribuição à comunidade acadêmica e sociedade em 
geral, como atende a seus anseios, qual a sua responsabilidade social, por que e para que existe, qual sua missão, a que se propõe, quais são os seus princípios, quais são as suas atividades fundamentais, como são executadas, como as pessoas que a integram são e estão mobilizadas para atingirem resultados, e por último, que resultados se pretende atingir.

No entanto, se considerarmos que a Biblioteca Universitária está vinculada a uma Instituição de Ensino Superior - (IES), todas as questões citadas anteriormente necessitam estar em pleno acordo com os seus motivos, necessidades e expectativas, assim como com a sua missão, seus objetivos, estratégias, metas e políticas. Dessa forma, a integração entre a BU e a IES passa a ser um requisito básico para o desenvolvimento de um Sistema Gestão e, principalmente, para a excelência administrativa da BU.

Embora se reconheça a necessidade de um adequado preparo gerencial para se administrar uma biblioteca, falta para muitos bibliotecários compreendêla como uma organização. Essa falta de visão faz com que não administrem as Bibliotecas Universitárias a partir dos princípios de gestão aplicados às demais organizações. Ter a visão de uma BU como uma organização passa a ser fundamental para os bibliotecários administradores, na medida em que os auxilia na própria tarefa de administrar e no desenvolvimento de instrumentos de gestão específicos para suas bibliotecas.

Para uma BU ter um bom desempenho necessita, sobretudo, de bons instrumentos de gestão, do envolvimento de toda a equipe, bem como de uma predisposição da direção para, no mínimo, enfrentar as necessidades da comunidade acadêmica e as exigências dos critérios de avaliação utilizados pelo Ministério da Educação (MEC) ${ }^{6}$. É importante ressaltar que, para uma IES permanecer atuante, necessita do reconhecimento dos seus cursos junto ao MEC e, para isso, precisa contar com a eficácia do seu órgão fundamental de apoio - a Biblioteca -, o qual é um setor em destaque a ser avaliado pelas comissões de reconhecimento de cursos.
O SGBU pretende aliar os conceitos de Administração com a aplicação prática no ambiente das BUs, oferecendo ao profissional bibliotecário uma abordagem capaz de ser compreensível e aplicável à sua realidade. Mas de nada vale um esforço isolado, se a BU não conseguir da IES o devido apoio, incentivo e reconhecimento de sua importância para o trinômio ensino, pesquisa e extensão, ou ainda, se o bibliotecário administrador não se esforçar para mobilizar sua equipe e conquistar este espaço. Sem essa integração, tornarse-á muito difícil a implantação de um Sistema de Gestão, pois ele exige envolvimento e comprometimento do bibliotecário administrador, da sua equipe e da IES à qual a BU se encontra vinculada.

Buscando transcender a técnica e minimizar essas dificuldades, pretende-se com o presente estudo oferecer subsídios teórico-práticos que auxiliem o bibliotecário na gestão de Bibliotecas Universitárias. Todavia, levando-se em consideração que cada BU possui peculiaridades técnicas, administrativas, culturais e tecnológicas, o estudo desenvolvido pretende ser entendido como uma base conceitual, associada à práxis cotidiana, servindo de orientação à administração de qualquer BU, independente do seu espaço físico, do tamanho do acervo, dos recursos humanos e do tipo de IES à qual pertença (Universidade, Centro Universitário, Centro Federal de Educação Tecnológica (CEFET), Centro de Educação Tecnológica (CET), Faculdade Integrada, Faculdade Isolada, Instituto Superior de Educação pluridisciplinares, públicas ou privadas $)^{7}$-, pelo fato de ter assumido uma tendência universalista. No entanto não deve ser aplicado como um modelo pronto.

Paralelamente ao desenvolvimento do SGBU, foram conduzidas as implementações na BU selecionada pela autora, o que permitiu uma interação dinâmica entre o sujeito (bibliotecários, funcionários e usuários) e o objeto pesquisado (Biblioteca Universitária). O SGBU proposto é composto por seis subsistemas: Subsistema Institucional, Subsistema Gerencial, Subsistema Operacional, Subsistema de Organização, Subsistema Humano-Comportamental e Subsistema Ambiental.

\footnotetext{
6 Leitura complementar: DZIEKANIAK, Cibele V. Participação do bibliotecário nas comissões de avaliação do Ministério da Educação (MEC) nos processos de reconhecimento de cursos de graduação. Biblos: Revista do Departamento de Biblioteconomia e História, v. 18, 2006. Disponível em: <http://www.seer.furg.br/ojs/index.php/dbh/article/view/90>. Acesso em: 15 dez. 2007.

7 Classificação acadêmica das Instituições de Educação Superior apresentada pela Secretaria de Educação Superior (SESu). Disponível em: <http://portal.mec.gov.br/sesu >. Acesso em: 01 nov. 2007.
} 


\section{SISTEMA DE GESTÃO PARA BIBLIOTECA UNIVERSITÁRIA (SGBU)}

O SGBU agrupa o conjunto de conceitos e técnicas de gestão em seis subsistemas, conforme esclarecido anteriormente, de acordo com seus propósitos:

- o Subsistema Institucional proporciona instrumentos que auxiliam no estabelecimento da razão de ser de uma BU, da sua finalidade básica, do seu compromisso com a IES - de acordo com suas crenças, valores, convicções e expectativas -, do seu negócio, da sua maneira de pensar e agir, bem como do seu posicionamento e relacionamento com todas as partes que compõem seus ambientes internos e externos;

- o Subsistema Gerencial reúne instrumentos que auxiliam o bibliotecário administrador a estabelecer os rumos a serem seguidos, os resultados pretendidos, os objetivos e estratégias, isto é, auxiliam a definir o que a BU deve fazer e se o que está sendo feito está de acordo com seus objetivos;

- O Subsistema Operacional fornece instrumentos para que a direção defina quais as atividades fundamentais para a BU cumprir suas finalidades e como cada uma delas será executada, ou seja, envolve definições dos métodos, normas, materiais, nível de informatização e instalações necessárias para a BU cumprir suas finalidades;

- o Subsistema de Organização auxilia a administração a especificar as funções necessárias para a realização das atividades da BU, a dividir essas funções em setores e/ ou seções, a delimitar a decisão de cada um, bem como a designar recursos humanos para a execução das funções;

- o Subsistema Humano-Comportamental auxilia o bibliotecário administrador a motivar, integrar e a ativar a equipe, de acordo com os resultados almejados e com as finalidades da BU;

- o Subsistema Ambiental proporciona não só um maior envolvimento da BU com a questão ambiental, como também contribui para que a responsabilidade ambiental da Biblioteca Universitária e do profissional bibliotecário seja cumprida.

\section{Subsistema Institucional}

O Subsistema Institucional torna-se fundamental para a administração de BU, na medida em que propicia instrumentos para que o bibliotecário administrador oriente suas ações em direção aos resultados pretendidos, tenha clareza das finalidades internas e externas pelas quais a BU existe e é mantida, e conheça a sua razão de ser, de acordo com as expectativas, crenças, valores e necessidades da IES à qual está vinculada. Responder claramente às questões: "por que a Biblioteca Universitária existe?" "o que faz?" "o que quer ser?" e "no que acredita?" constitui a base para o seu desenvolvimento e aperfeiçoamento.

O Subsistema Institucional é composto pelos seguintes instrumentos: negócio, missão, visão e princípios. Esse conjunto de instrumentos será denominado aqui como Filosofia da Biblioteca, mas também é conhecido por outras denominações (quando se trata de organizações como um todo), tais como: Filosofia Empresarial, Identidade Organizacional, Filosofia Corporativa, Ideologia Central, entre outros.

Para definir o negócio, torna-se necessário explicitar a área ou áreas nas quais a Biblioteca Universitária atua ou pretende atuar. De acordo com Arantes (1998, p. 110), negócio é o "conjunto de necessidades sociais que a empresa se dispõe a atender", buscando servir a um mercado-alvo, o qual se caracteriza pelas peculiaridades e necessidades dos seus clientes (Valadares, 2002). Nas BUs, os clientes/ usuários podem ser os docentes, discentes, egressos, funcionários, ou, até mesmo, a comunidade externa. Essa definição torna-se importante, porque justifica a razão de ser da BU, auxiliando no cumprimento da missão.

A definição do negócio precisa ser clara e não deve centrar-se somente nos produtos ou serviços oferecidos. Sua visão deve ser ampla, expandindo seu foco de atuação, ou seja, aumentando a capacidade de enxergar oportunidades e ameaças. Torna-se importante,pois, centrar sua análise nos benefícios almejados pelos usuários, bem como nas suas peculiaridades e necessidades. 
A missão é a razão de ser da BU, sua finalidade básica, seu compromisso com a IES. Segundo Almeida (2001 , p.28), "o conceito de missão está ligado à razão de ser, que pode ser de uma organização, unidade ou profissional. Sendo que uma unidade deve ter sintonia com a missão da organização da qual faz parte, além de considerar sua própria razão de ser, da mesma forma que o profissional." Vale ressaltar que a formulação da missão de uma BU deve estar sempre em consonância com a missão da IES à qual pertença.

De acordo com Valadares (2002), a missão funciona como diretriz da organização. Seu tempo de duração é indeterminado, podendo ficar por longo tempo, ou ser alterada, de acordo com o comportamento dos consumidores, com as necessidades da sociedade e com as tecnologias, que se modificam com o passar dos tempos. Deve ser clara, objetiva, entendida e divulgada por todos os colaboradores da organização, pois não deixa de ser o seu objetivo estratégico, já que todos os recursos serão direcionados para as áreas de atuação que forem estabelecidas.

Desse modo, a missão da BU deverá ser trabalhada e divulgada em todos os seus setores/ serviços/divisões/seções, como, por exemplo, aquisição, processamento técnico, referência, circulação, comutação bibliográfica, periódicos, multimídia, entre outros, e seu tempo de duração deverá ser estabelecido de acordo com as exigências dos usuários, com o advento de novas tecnologias e com o comportamento da sociedade.

Visão, segundo Oliveira (2002), representa o que a organização quer ser, em outras palavras, e direcionando-se para a realidade das BUs, visão é a idealização de um futuro, a descrição de um "sonho" bem abrangente, não limitado por tempo. O papel da visão também é o de motivar e inspirar a equipe de trabalho, bem como alinhar seus esforços, a fim de promover sinergia interna, pois, ficando claro o estado futuro que a BU deseja, "bastará" construí-lo. Assim, para que essa sinergia interna seja promovida, todos os colaboradores precisam tomar conhecimento do que vem a ser a visão da $B U$ em que atuam, como também passar a desejá-la, e isto só se tornará possível, se houver um bibliotecário administrador promovendo-a e concentrando seus esforços na sua concretização.

Os princípios, segundo Arantes (1998, p. 111 ),

"[...] representam a maneira de pensar e agir da empresa. Eles estabelecem o posicionamento e o relacionamento da empresa com todas as partes que compõem seus ambientes interno e externo. Os princípios têm, portanto, uma abrangência ampla."

Embora os princípios envolvam vários aspectos relevantes de uma BU como, por exemplo, produtos/ serviços, usuários, fornecedores, meio ambiente, colaboradores, inovação/mudanças, responsabilidade social, ética profissional, entre outros, não precisam ser extensos, visto que, nesse momento, apenas será estabelecido "o que" se acredita como certo e leal, e não "o como" será realizado.

De acordo com Valadares (2002), os princípios, ou crenças e valores constituem a base de convicção nas quais os colaboradores acreditam, e de acordo com as quais agem e decidem, dando sustentação às ações administrativas. A divulgação desses princípios perante a equipe de trabalho irá permitir maior compreensão das decisões internas, bem como conduzirá a um melhor entendimento das ações e do comportamento gerencial.

Para que a Filosofia da Biblioteca seja um bom instrumento de gestão, torna-se necessário atender a um conjunto de condições como, por exemplo, tomar certos cuidados em relação a sua concepção (a prática e as definições da Filosofia devem caminhar juntas) e com a comunicação e especificação clara (a Filosofia deve ser conhecida, entendida e aceita por todos os colaboradores). A Filosofia da Biblioteca também se preocupa com as relações da organização com os clientes e deve ser gerenciada por algum responsável, a fim de garantir sua integridade. No caso das Bibliotecas Universitárias, compete ao bibliotecário administrador a responsabilidade pela Filosofia da Biblioteca, para que se tenha certeza de que a Filosofia está sendo adequadamente comunicada, entendida, aceita e praticada pelos outros colaboradores.

\section{Subsistema Gerencial}

O Subsistema Gerencial caracteriza-se por ser um tipo de instrumento de gestão que, segundo Arantes (1998, p.129), auxilia a administração a estabelecer "com clareza os resultados a serem atingidos e os caminhos a serem seguidos, em consonância com a missão, objetivos e princípios empresariais. Ele também auxilia a administração a implementar as ações e 
verificar se sua execução está adequada, e a avaliar permanentemente se os resultados obtidos estão coerentes com os previstos."

Para que o sucesso da BU seja assegurado, torna-se importante definir os produtos a serem oferecidos aos usuários (livros, e-books, periódicos, periódicos eletrônicos, mapas, bases de dados, dvds, cd-roms, disquetes, teses, informativos, etc.), e, conseqüentemente, as tecnologias a serem utilizadas e o tipo de suporte (impresso, eletrônico, entre outros), e os usuários a serem atendidos (discentes, docentes, funcionários, alunos egressos, alunos do ensino médio, comunidade em geral etc.).

Essas definições são importantes, uma vez que auxiliam o bibliotecário administrador na tarefa não apenas de definir os rumos a serem seguidos e os resultados a serem conseguidos, bem como de implementar as ações necessárias, verificar se a sua execução está correta e avaliar como a BU está indo, isto é, se os resultados obtidos estão de acordo com os planejados.

Portanto o Subsistema Gerencial proposto no presente estudo seguirá o modelo sugerido por Arantes (1998) que o define como simples e útil na prática. Seus componentes são: parâmetros de resultados, processo gerencial e estilo gerencial:

Parâmetros de resultados: é por meio dos parâmetros de resultados que o bibliotecário administrador e sua equipe irão definir os aspectos relevantes para planejar os resultados e avaliar o desempenho da BU. Segundo Arantes (1998, p.131), "estes são definidos para cada atividade da tarefa empresarial e podem eleger aspectos tais como satisfação dos clientes, inovação, conduta, rentabilidade, liquidez, desenvolvimento da equipe de colaboradores, relações que a empresa mantém no ambiente externo e interno, etc.", ou seja, são instrumentos que auxiliam a direção a agir em direção aos resultados pretendidos.

Embora seja importante definir parâmetros de resultados para as principais atividades, não se torna viável trabalhar com um grande número deles. $\bigcirc$ fundamental é estabelecer os aspectos relevantes da BU e definir os parâmetros de resultados representativos para sua realidade, estando esses sempre associados à Filosofia da Biblioteca. Desta forma, fica mais fácil divulgar e trabalhar os parâmetros com a equipe de colaboradores.
Para Arantes (1998), a seleção dos parâmetros relevantes também pode ser feita de acordo com as fases evolutivas da organização, refletindo neles os aspectos mais importantes de cada estágio. No caso das Bibliotecas Universitárias, pode ser que a Biblioteca " $Y$ " se encontre num estágio em que a informatização esteja sendo o fator mais crítico; em outro estágio, pode ser que seja a capacitação da equipe, entre outros. Logo, cabe selecionar os parâmetros mais relevantes para cada estágio e trabalhá-los por etapas.

Após sua definição, os parâmetros de resultados devem ser entendidos por todos os colaboradores da BU, além de serem auto-explicativos e de fácil entendimento, para não darem margens a várias interpretações. A clareza dos critérios de medição de cada parâmetro também é outro fator relevante nessa etapa.

Processo gerencial: tem como função definir as funções administrativas a serem utilizadas na Biblioteca Universitária, o que as compõe, como serão realizadas, a forma como serão integradas e os tipos de planos que serão utilizados. $\bigcirc$ modelo de processo gerencial proposto no SGBU será constituído pelas funções de Planejamento, Direção e Controle. A função administrativa Organização será tratada como um subsistema, ou seja, é o quarto Subsistema do SGBU (Subsistema de Organização).

\section{- Planejamento}

Para a execução do planejamento, adotou-se o processo sugerido por Arantes (1998), que se constitui de cinco fases: (1) definição dos resultados a alcançar; (2) avaliação das condições internas e externas que favorecem ou dificultam a consecução desses resultados; (3) a formulação de alternativas de ação; (4) a avaliação das alternativas e a tomada de decisão para escolha da melhor alternativa; (5) o detalhamento da alternativa escolhida.

A definição clara sobre o que se deseja para o futuro da BU é um dos requisitos do planejamento. Barbalho e Beraquet (1995, p. 11 -12) ressaltam que:

Trabalhar com ambiente significa trabalhar com mudanças e, nessa época de mudanças, Informação e planejamento são elementos 
indispensáveis para o sucesso de qualquer organização. A Unidade de Informação pode ser o instrumento que viabiliza a aceleração de mudanças numa organização, já que a informação é hoje considerada uma vantagem competitiva que agrega valor aos produtos ou serviços oferecidos. Planejamento, por outro lado, é atividade importante e rotineira tanto para os indivíduos (que planejam seu dia, as suas férias, a compra do carro etc.), como para organizações (que planejam os seus investimentos, a sua produção, a sua atuação no mercado etc.).

Dessa forma, é na primeira fase do seu processo - definição dos resultados - que o bibliotecário administrador e os supervisores de cada serviço ou setor passam a criar o futuro da BU. Todavia, para se chegar a este futuro almejado, é preciso vencer etapas, gradativamente, de acordo com as condições e realidade de cada IES, isto é, os objetivos maiores só serão atingidos, à medida que os estágios para se chegar até eles forem vencidos e para isso, a motivação e perseverança são duas aliadas fundamentais. Portanto, para fixar os resultados a serem atingidos, o bibliotecário administrador e os supervisores devem basear-se nos parâmetros de resultados, os quais precisam ser passíveis de execução, medição e avaliação.

Na segunda fase - avaliação das condições são identificadas e avaliadas as condições favoráveis ou desfavoráveis, internas ou externas, atuais e futuras que possam interferir na obtenção e no sucesso dos resultados almejados, ou seja, essa avaliação não só proporciona ao bibliotecário administrador e aos supervisores um conhecimento dos pontos fortes e fracos da sua BU, como também das suas oportunidades e ameaças.

Na terceira fase do processo de planejamento formulação de alternativas - define-se a ação a ser tomada para alcançar os resultados pretendidos. Tornase importante formular alternativas para que as oportunidades e pontos fortes sejam aproveitados e os pontos fracos e ameaças reduzidos ou mesmo eliminados. Desse modo, considerar apenas uma alternativa de ação pode ser um fator limitante para se chegar ao melhor plano.

Na quarta fase - avaliação e escolha - o bibliotecário administrador e os supervisores escolherão, dentre as alternativas formuladas na terceira etapa, a que melhor contribuir para o alcance dos resultados almejados. Nesse sentido, essa fase assume grande importância no processo de planejamento, porque definirá o curso de ação a ser seguido.

A última fase - detalhamento do plano - é o oposto da terceira. Nesse momento, a alternativa escolhida deve possuir um alto nível de detalhamento para que o plano possa ser implementado e executado corretamente, bem como alocado às divisões, departamentos, seções ou grupos de trabalho de uma BU. Sendo o plano a conseqüência do planejamento, torna-se importante definir os tipos específicos de planos a serem abordados (por exemplo: objetivos; políticas; procedimentos; normas; regulamentos; programas; projetos; orçamentos), e o limite de tempo em que essas decisões são válidas (planos temporários ou planos permanentes). Tais definições auxiliam os colaboradores a entenderem os planos e facilitam a tomada de decisão do bibliotecário administrador, uma vez que ele poderá escolher o plano adequado para cada tipo de decisão.

- Direção

A execução da função administrativa direção será constituída por quatro fases: (1) designação dos responsáveis; (2) comunicação dos planos; (3) desenvolvimento da equipe; (4) orientação e coordenação (Arantes, 1998).

Na primeira fase - designação dos responsáveis - selecionam-se as pessoas, como as seções/divisões/ setores/serviços (processamento técnico, referência, circulação, entre outros) necessários para execução dos planos e obtenção dos resultados, isto é, delega-se a parcela de responsabilidade de cada colaborador, de acordo com os níveis de autoridade, com as funções e com as áreas competentes. Portanto, para que a direção possa cumprir com eficácia essa função, torna-se necessário que os planos desenvolvidos no planejamento sejam bem detalhados e que a estrutura organizacional da BU seja clara e coerente.

Na segunda fase - comunicação dos planos comunicam-se os planos às pessoas responsáveis pelas suas execuções e resultados. Nesse sentido, tal momento assume grande importância no processo de direção, porque depende dele a motivação e promoção do entendimento correto e uniforme das pessoas quanto 
aos resultados a alcançarem, bem como a garantia do comprometimento dessas na execução dos planos. Fazer, portanto, com que os envolvidos compreendam corretamente o que deve ser feito e que contribuam para que os resultados estabelecidos sejam alcançados passa a ser o objetivo dessa fase.

A terceira fase - desenvolvimento da equipe tem como objetivo preparar as pessoas responsáveis pela execução dos planos, isto é, promover a capacitação e desenvolvimento da equipe. Todavia a identificação dos requisitos e das qualificações exigidas para a execução dos planos já deve ter sido feita no planejamento, na medida em que os programas de capacitação necessitam de integração com os planos. A direção deve responsabilizar-se apenas pela execução dos programas de capacitação.

A quarta e última fase - orientação e coordenação - tem como objetivo colocar os planos em prática, cabendo ao bibliotecário administrador garantir que sua execução seja adequada. As atividades de orientação e coordenação da execução dos planos fazem parte dessa fase, ou seja, a orientação auxilia a administração a descobrir se a equipe está enfrentando algum problema na execução dos planos, e serve também para realizar eventuais ajustes nos planos decorrentes de algum imprevisto. Os ajustes devem ser apenas adequações dos detalhes operacionais. Se forem necessárias maiores alterações nos planos, eles devem ser revistos na função planejamento. A coordenação serve para garantir a integração das diversas atividades necessárias para se colocar em prática a execução de um plano, uma vez que se realizam muitas atividades diversificadas, além de serem envolvidos colaboradores de diferentes setores.

\section{- Controle}

Para a execução da função administrativa controle, adotaram-se as seguintes fases, sugeridas por Arantes (1998, p. 171): (1) a avaliação dos resultados reais em relação aos planejados e identificação de eventuais desvios; (2) a comunicação dos desvios aos responsáveis por sua correção; (3) o acompanhamento dos efeitos das ações corretivas até que os desvios sejam eliminados.

Na primeira fase - avaliação dos resultados confrontam-se os resultados previstos com os realizados, no intuito de se verificar se o desempenho está de acordo ou não com os padrões desejados. Se não estiverem de acordo, será necessário corrigir os desvios ocorridos.

Compete à segunda fase - comunicação dos desvios - comunicar os desvios ocorridos aos responsáveis por sua correção. Para isso, conforme mencionado na função direção, a estrutura organizacional da BU precisa ser clara e coerente, isto é, os níveis de autoridade precisam estar definidos com clareza. Também se torna fundamental a utilização de bons instrumentos para a comunicação dos desvios (como reuniões de avaliação de desempenho para analisar os relatórios e não simplesmente relatórios confusos, que possam vir a gerar interpretações incorretas ou dúvidas), para evitar mal-entendidos por parte dos responsáveis pelas correções e para proporcionar mais agilidade na correção dos desvios identificados.

Na última fase - acompanhamento das correções - acompanham-se os pontos em que foram detectados os desvios, para que se tenha certeza de que as correções foram bem executadas e que ficaram de acordo com o desempenho esperado.

Estilo gerencial: significa a forma como o bibliotecário administrador irá executar o processo gerencial, isto é, o estilo de liderança predominante. Existem várias formas de se executar o processo gerencial e sua execução não se dá apenas pelos aspectos técnicos, mas também pelas questões humanocomportamentais. Para se gerenciar uma equipe não basta levar em consideração apenas os prós e os contras dos diversos estilos existentes (autocráticos, democráticos, liberais, centralizados, descentralizados, entre outros), é preciso considerar também as variáveis de natureza humana.

Todas as funções administrativas - planejar, dirigir e controlar - precisam ser orientadas uniformemente pelo estilo gerencial adotado pelo bibliotecário administrador, para que haja coerência no processo gerencial.

Arantes (1998, p.180) alerta que não existe apenas um estilo gerencial, ou seja,

o estilo gerencial não é estático. Ele varia conforme as características do ambiente interno e externo de uma empresa em particular. [...] Varia também em função do sistema de valores do gerente e da maturidade da equipe de subordinados. Não há, portanto, um estilo certo 
ou errado. Há um estilo adequado para cada situação específica.

estilo gerencial, portanto, torna-se um instrumento de auxílio ao bibliotecário administrador, pois ajuda na promoção da integração, motivação e do entusiasmo da equipe em relação aos resultados pretendidos.

\section{Subsistema Operacional}

Subsistema Operacional tem a função de auxiliar o bibliotecário administrador a definir quais as atividades indispensáveis para a BU cumprir suas finalidades e como devem ser executadas, a fim de assegurar a eficiência e contribuir com os resultados.

Todavia, para que a eficiência possa ser assegurada de forma global, a direção necessita incluir no Subsistema Operacional todas as atividades necessárias para a BU cumprir suas finalidades e não apenas algumas ou as que acharem mais importantes, visto que esse Subsistema caracteriza-se pelo conjunto dessas atividades, de forma integrada. Caso contrário, algumas atividades da BU funcionarão bem e outras não, comprometendo a eficiência global.

Nesse subsistema, também se torna viável considerar as atividades externas, ou seja, aquelas realizadas pelas organizações que estão fora dos limites da Biblioteca Universitária, como, por exemplo, as atividades realizadas pelos fornecedores de livros, periódicos, entre outros materiais, ou pelo serviço de manutenção e limpeza etc. Embora essas atividades sejam desempenhadas por terceiros, implicam diretamente na sua eficiência, já que o comprometimento com os clientes e a responsabilidade com o produto final será sempre da BU.

De acordo com Arantes (1998, p.195), "o Subsistema Operacional define a tecnologia utilizada para a produção das coisas tangíveis e intangíveis necessárias para que a empresa cumpra suas finalidades". Desse modo, a tecnologia utilizada no Subsistema Operacional do SGBU envolverá os seguintes componentes: métodos, normas, materiais, informatização e instalações.

Métodos: são utilizados para definir a seqüência e a maneira como cada atividade deve ser executada. Um exemplo da utilização de métodos em uma BU poderia ser no processo de aquisição, na qual a atividade solicitação de orçamentos dar-se-ia por meio dos seguintes métodos: preparar listagem com os títulos, autores e editoras das obras a serem orçadas; contatar fornecedores; enviar listagem das obras por e-mail ou fax; avaliar propostas; negociar valores etc.

Normas: determinam as regras para a execução de cada atividade e auxiliam na promoção da padronização. Por exemplo, as normas a serem seguidas na execução da atividade solicitação de orçamento poderiam ser: receber orçamentos somente por e-mail; entregar as notas fiscais na tesouraria sempre na data de entrega das obras, entre outras.

Materiais: são os insumos utilizados para a realização das operações. Na atividade solicitação de orçamento, por exemplo, poderiam ser utilizados os seguintes materiais: fax ou computador (para enviare receber os orçamentos; pastas e/ou arquivos (para armazenar orçamentos, notas fiscais), entre outros.

Informatização: para que os processos possam contribuir efetivamente para a eficiência da BU, devem ser trabalhados de maneira integrada. Sendo assim, essa questão também precisa ser considerada no momento da aquisição de um software. Uma forma de assegurar a integração seria a adoção de softwares integrados de gestão de bibliotecas, já que trabalham as principais funções de uma biblioteca, por meio de seus diversos módulos, de forma integrada. Conforme Dziekaniak (2003), esses softwares de gerenciamento devem apresentar algumas funções básicas, tais como: encomenda e aquisição; catalogação; indexação; classificação; acesso à Internet - Catálogos em Linha de Acesso Público (OPAC); controle de circulação; informações gerenciais.

Segundo Côrte e Almeida (2000, p. 13), "a modernização das bibliotecas está diretamente ligada à automação de rotinas e serviços, com o intuito de implantar uma infra-estrutura de comunicação para agilizar e ampliar o acesso à informação pelo usuário, tornando-se necessária uma ampla visão da Tecnologia da Informação e sua aplicação nas organizações." Contudo também se torna necessário considerar que as ineficiências de uma BU não serão solucionadas apenas com a aquisição de um software de gestão, pois a informatização veio para contribuir com a eficiência global da BU, mas o fator principal a ser considerado para a busca da melhoria é, sem dúvida, o conhecimento detalhado e aprofundado do seu Subsistema Operacional. 
Voltando para a realidade das BUs, um bom exemplo para ilustrar a automatização das ineficiências poderia ser a questão da informatização do serviço de aquisição. Se este serviço apresentasse como ineficiência a contínua aquisição de obras já existentes no acervo, não bastaria apenas automatizar os pedidos com formulários eletrônicos e achar que, com o serviço informatizado,, os problemas estariam resolvidos. Isto seria apenas uma substituição das planilhas em papel por eletrônicas. $O$ essencial seria realizar um estudo do serviço de aquisição, identificar as ineficiências, suas possíveis causas e, por último, as possíveis soluções, para então utilizar a tecnologia de maneira satisfatória, ou seja, primeiramente dominar o processo, para depois pensar na informatização, de acordo com suas reais necessidades e de maneira a agregar valor à eficiência operacional como um todo.

Todavia, embora a Tecnologia da Informação (TI) não tenha sido explorada nesse Subsistema como realmente mereceria, torna-se oportuno ressaltar a sua importância dentro da Biblioteconomia. Segundo Dziekaniak (2003, p. 204),

a TI não deve ser vista apenas como o conjunto de ferramentas tecnológicas, uma vez que influencia nas transformações de paradigmas e de práticas. Dentro deste enfoque, entende-se que ela deveria constituir uma nova área dentro da Automação de Bibliotecas, ou melhor, substituindo-a, pois a supera.

Instalações: este componente do Subsistema Operacional envolve não só o espaço físico (podendo estar adequado ou não ao tamanho do acervo ou precisando ser expandido, reformado, etc.), como o acesso ao acervo (aberto ou fechado), a sinalização utilizada (placas, cartazes, cores), a decoração (padrão da IES ou diferenciada), o mobiliário (confortável, ergonômico, etc.) bem como as condições ambientais indicadas para uma boa conservação do acervo (temperatura adequada, controle da umidade do ar, luminosidade, etc.).

Os componentes do Subsistema Operacional precisam estar interligados, pois uns dependem dos outros. Um exemplo dessa dependência entre os componentes do Subsistema Operacional de uma BU poderia ser observado no momento da aquisição de um sistema de segurança para o acervo. Uma decisão como essa implicaria novos métodos para a execução das atividades diárias, exigiria mudanças nos equipamentos, nas normas e até mesmo nas instalações.
Não obstante, para avaliar e conceber o Subsistema Operacional deve-se, primeiramente, relacioná-lo à Filosofia da Biblioteca (negócio, missão, visão, princípios) e, após, identificar suas partes componentes e o que se espera de cada uma delas, trabalhando-as sempre de maneira integrada. Segundo Arantes (1998, p. 201-202), "para que possa ser um instrumento efetivamente útil, o Subsistema Operacional deve ser concebido no máximo nível de detalhe, e este nível é aquele que nos permite saber como cada atividade é executada." Nesse sentido, para cada processo ou atividade da BU devem ser relacionados os componentes do Subsistema Operacional: métodos, normas, materiais, informatização e instalações.

Portanto, para um bom funcionamento do Subsistema Operacional, os componentes devem ser trabalhados de maneira integrada, uma vez que todos estão interligados entre si. A eficiência e qualidade do produto/serviço final, assim como a satisfação dos clientes dependem dessa relação de integração.

\section{Subsistema de Organização}

Conforme mencionado anteriormente, a função administrativa Organização será tratada no SGBU como um subsistema, o Subsistema de Organização. De acordo com Arantes (1998, p. 220), a organização

[...] envolve a distribuição da tarefa empresarial em unidades organizacionais - diretorias, divisões, departamentos, setores, a definição dos papéis e responsabilidades dessas unidades, seus níveis de autoridade e a designação de pessoas competentes para executar as funções alocadas a cada uma dessas unidades organizacionais. [...] Ela define quem faz o quê.

Desse modo, o Subsistema de Organização auxilia o bibliotecário administrador a organizar a BU internamente, alcançando melhores resultados.

Arantes (1998) recomenda quatro componentes fundamentais para compor o Subsistema de Organização. São eles: as funções, a estrutura organizacional, o nível de autoridade e as pessoas responsáveis pelas funções. Abaixo, estes componentes serão analisados e detalhados para que se tenha uma melhor compreensão deles, no âmbito das BUs.

Funções: uma vez definidas as atividades que irão compor os processos da $\mathrm{BU}$, por meio do 
Subsistema Operacional, torna-se mais fácil definir as funções. Serão essas atividades que determinarão quais as funções necessárias para integrar a organização da BU. Porém, à medida que uma BU se expande e cria oportunidades e estratégias, as novas funções também devem ser previstas; caso contrário, torna-se impossível atender satisfatoriamente às necessidades dos usuários.

Segundo Arantes (1998, p.227), "uma das características das funções é a natureza de seus objetivos: institucionais, gerenciais e operacionais." As funções institucionais de uma BU são destinadas a cuidar dos aspectos relacionados à Filosofia da Biblioteca - negócio, missão, visão e princípios -, isto é, além de defini-la e disseminá-la, também devem contribuir para o seu entendimento e prática, certificando-se sempre de que os resultados alcançados estão ou não de acordo com Filosofia da Biblioteca. Essas funções também podem ser exercidas pelo diretor da $B U$ e bibliotecários que exerçam algum tipo de supervisão. As funções gerenciais ficam encarregadas de realizar o planejamento, ou seja, elaborar os planos, implantá-los, acompanhá-los e avaliá-los. Essas funções podem ser exercidas, por exemplo, pelo diretor da $\mathrm{BU}$ e bibliotecários que exerçam algum tipo de supervisão. As funções operacionais executam todas as atividades que integram os processos de uma BU e devem assegurar a eficiência, produtividade e qualidade. Tais funções são exercidas por todo o quadro de pessoal da BU, ou seja, desde os bibliotecários do processamento técnico, referência, aquisição, até os auxiliares.

A execução de qualquer função em uma Biblioteca Universitária, porém, exige diferentes tipos de conhecimentos e especializações, tais como: formação em Biblioteconomia (para ocupar as funções de direção, processamento técnico, referência, aquisição, etc.), especializações em Marketing ou Comunicação Social (para trabalhar a divulgação dos produtos e serviços da BU para a comunidade acadêmica), Informática (para dominar as ferramentas do software de gestão utilizado), Conservação/Restauração (para recuperar obras deterioradas e conservar o acervo), entre outras. Sendo assim, "se os requisitos de conhecimentos não forem adequadamente identificados, certamente a execução da função será prejudicada, haverá maiores dificuldades na alocação e desenvolvimento das pessoas designadas para a função e outras implicações." (Arantes, 1998, p.233). Além disso, torna-se necessário traçar os perfis desejados para cada função.
Outro fator importante a ser considerado na definição das funções são os resultados esperados de cada uma delas. Essa definição é tão importante quanto saber o que deverá ser feito por cada uma. Isso faz com que as pessoas realizem suas atividades de maneira consciente, porque já sabem o tipo de contribuição que a BU espera delas. Conforme Arantes (1998, p. 245), "não há processo de recrutamento e seleção que consiga ser eficiente sem uma visão clara do porquê de uma função, das responsabilidades que envolve e dos requisitos que exige."

Estrutura organizacional: conforme mencionado anteriormente no capítulo Funções Administrativas, a estrutura organizacional deve ser pensada sempre de maneira flexível e não como algo fixo, pois uma $\mathrm{BU}$ encontra-se inserida em um ambiente instável (economicamente, socialmente, culturalmente, tecnologicamente) e, portanto, propícia a enfrentar ameaças ou mesmo oportunidades. Dessa forma, as Bibliotecas Universitárias necessitam, sobretudo, de dinamismo, de maneira que a estrutura organizacional possa ser ajustada e reajustada sempre que necessário.

O organograma representa graficamente a estrutura organizacional e tem por objetivo

- a divisão do trabalho, mediante o
fracionamento da organização, em unidades de
direção, assessorias, conselhos, gerências,
superintendências, departamentos, divisões,
serviços, setores etc.; - a relação superior
subordinado, o que deixa implícitos os
procedimentos relativos à delegação de
autoridade e responsabilidade [...].
(Araújo, 2001, p. 131).

Existem diversas técnicas para agrupar as funções que irão integrar uma BU, ou seja, várias formas de departamentalização, as quais podem, também, ser utilizadas de forma combinada, conforme esclarecido no capítulo Funções Administrativas. Nesse sentido, sugerese no presente estudo a utilização de duas técnicas para agrupar as funções de uma BU: departamentalização por serviços e departamentalização por processos.

Inicialmente, utiliza-se a primeira técnica para agrupar os serviços oferecidos pela BU. Após agrupar os serviços prestados, utiliza-se a técnica de departamentalização por processos, ou seja, agrupamse as operações de cada serviço em partes menores, constituindo processos. Dessa forma, o diretor da BU pode designar um bibliotecário supervisor para cada serviço. Tal funcionário irá exercer funções institucionais 
e gerenciais, isto é, além de contribuir para o entendimento e prática da Filosofia da Biblioteca e certificar-se de que os resultados alcançados pelo serviço de sua responsabilidade estão ou não de acordo com ela,I também deve elaborar os planos, implantá-los, acompanhá-los e avaliá-los, assim como controlar os resultados do serviço pelo qual é encarregado. Isso permite à $\mathrm{BU}$ um equilíbrio entre as funções institucionais, gerenciais e operacionais e não apenas orientação para as operações.

Outro requisito importante a ser estabelecido é o nível de autoridade, ou seja, o grau de autonomia que é dado pela IES à direção da BU, ou o grau de autonomia que é dado pela direção da BU aos seus colaboradores para tomarem decisões, nos mais diversos aspectos como, por exemplo: seleção ou demissão de pessoal; abono de multas, modificação nos processos, nos fluxos, nas políticas, nos métodos, no layout, entre outros. Conforme Arantes (1998, p.242), "o nível de autoridade é usualmente fixado formalmente, através de instrumentos gerenciais, principalmente as políticas e os orçamentos. [...] Além da clareza é preciso também que haja uma compreensão clara dessas definições."

O grau de centralização e descentralização das decisões também é outro ponto importante a ser analisado e definido. Inicialmente, o bibliotecário administrador tem que respeitar e saber o grau de autoridade para a tomada de decisão que the foi atribuído pela IES, e, em um segundo momento, definir - grau de autoridade para a tomada de decisão da sua equipe. Conforme citado anteriormente no capítulo Funções Administrativas, existem inúmeras vantagens e desvantagens a respeito desses tipos de modelos de decisões e a adoção de um ou outro, ou mesmo a variação de maior centralização até a mais alta descentralização dependerá, de acordo com Arantes (1998, p.243),

[...] das crenças e valores do administrador sobre a natureza humana. Os administradores que acreditam que o homem só trabalha sob supervisão direta, que deve ter seu desempenho controlado a cada tarefa específica, tendem a concentrar mais as decisões. Ao contrário, aqueles que incentivam a iniciativa e a obtenção de resultados dão autonomia a sua equipe.

Não se deve, porém, confundir os termos centralização e descentralização com o tipo de distribuição das funções às Bibliotecas (centrais e setoriais). "Ambos os termos estão associados ao grau de autoridade para tomar decisões." (Araújo, 1998, p.243). Nas BUs, por exemplo, não basta subdividir ou agrupar as funções entre as bibliotecas setoriais e achar que o Sistema de Bibliotecas é descentralizado, se, na verdade, apenas a execução das funções é realizada de maneira descentralizada, mas a autoridade para tomar decisões é centralizada na Biblioteca Central. Dessa forma, uma Biblioteca Universitária poderá ser considerada centralizada ou descentralizada, ou melhor, apresentará uma variação de maior centralização até a mais alta descentralização, de acordo com o grau de autoridade para tomar decisões que implique diretamente os resultados.

Bons resultados dependem diretamente das pessoas que estão envolvidas nos processos, pois são elas que irão garantir a eficiência e eficácia de uma BU. A informatização facilita inúmeras atividades, mas o fator principal a ser considerado para a busca da qualidade e dos melhores resultados é, sem dúvida, as pessoas. Por conseguinte, o desempenho de uma BU também depende da sinergia, isto é, do trabalho coordenado e cooperativo. Dessa forma, o êxito se torna maior do que se cada componente trabalhasse de forma isolada e sem cooperação. Sendo as pessoas as responsáveis pela execução das funções e obtenção dos resultados, torna-se fundamental sua participação, contribuição e envolvimento no processo decisório, nas mudanças e na melhoria contínua que ocorrem ao longo dos tempos.

Cabe, portanto, ao bibliotecário administrador utilizar-se dos instrumentos que o Subsistema Organizacional oferece, para que a distribuição das funções e a designação das pessoas sejam feitas de maneira eficaz, eficiente, integrada e para que sejam alcançados os melhores resultados.

\section{Subsistema Humano-Comportamental}

Nos subsistemas anteriores abordou-se com maior ênfase os instrumentos de gestão de natureza institucional e técnica. Esses instrumentos, porém, não são suficientes para que uma BU atinja seus objetivos. A excelência de uma BU depende do equilíbrio dos subsistemas técnicos e humanos. 
O componente humano-comportamental tornase de fundamental importância para o SGBU, pois são as pessoas que "[...] criam, desenvolvem e mantêm os empreendimentos; são elas que executam a tarefa empresarial e delas depende uma parcela significativa do sucesso ou insucesso dos empreendimentos empresariais." (Araújo, 1998, p.97). Entretanto, as pessoas que integram uma BU atuam em diferentes níveis organizacionais (diretor, supervisores, auxiliares) havendo, portanto relações de influências. Para Chiavenato (1999), a influência está ligada a dois conceitos importantes: poder e autoridade. A autoridade é considerada, por alguns autores, como um tipo de poder. Já o poder nada mais é do que outra forma de influência, um tanto mais ampla. Segundo Stoner e Freeman (1999, p.254), poder significa a "[...] capacidade de exercer influência; isto é, capacidade de mudar as atitudes ou o comportamento de indivíduos ou grupos."

Nesse contexto, surge a liderança que, de acordo com Chiavenato (1999, p.555),

[...] é, de uma certa forma, um tipo de poder pessoal. Através da liderança, uma pessoa influencia outras em função dos relacionamentos existentes. A influência é uma transação interpessoal, em que uma pessoa age no sentido de modificar ou provocar o comportamento de uma outra, de maneira intencional.

processo de liderança é muito complexo e envolve diferentes estilos, teorias e explicações, e, segundo o autor citado, ainda não existe uma abordagem ampla e universalmente aceita a respeito.

A liderança passa a ser, todavia, um dos fatores fundamentais para se atingir a eficácia nas BUs. $\bigcirc$ bibliotecário administrador que exerce a verdadeira liderança age como uma mola propulsora. Além de desenvolver novas visões a respeito do que a BU possa a vir ser e/ou fazer, também procura identificar necessidades de mudanças, bem como trabalha para satisfazer as necessidades e objetivos da organização e dos indivíduos que a integram.

Desse modo, o Subsistema HumanoComportamental caracteriza-se por ser um tipo de instrumento de gestão que serve para auxiliar " [...] a administração neste seu esforço de mobilizar as pessoas e de buscar a adequação do comportamento individual e coletivo aos requisitos da tarefa empresarial. Esses instrumentos são dirigidos à motivação, à ativação e à integração das pessoas." (Araújo, 1998, p.97).

A seguir, os componentes do Subsistema HumanoComportamental (Integração, Motivação e Ativação) serão detalhados, de acordo com sua natureza.

Integração: vários instrumentos de integração compõem este componente. Tais instrumentos, segundo Arantes (1998, p. 364), " [...] são destinados a promover o trabalho coletivo, estimulando a integração do indivíduo com os objetivos da empresa, sua participação em grupos e a relação entre os grupos." Conforme mencionado anteriormente, o sucesso de uma BU depende muito da sinergia e do trabalho em equipe, e para favorecer essa integração do grupo, o bibliotecário administrador poderá contar com alguns instrumentos, baseados em Arantes (1998), tais como:

- Filosofia da Biblioteca: na medida em que a Filosofia da Biblioteca orienta as ações em direção aos resultados pretendidos, esclarece as finalidades internas e externas pelas quais a BU existe e é mantida e determina a sua razão de ser, exerce um papel muito importante em relação ao aspecto comportamental da equipe. Por isso, torna-se fundamental que seja trabalhada com os colaboradores, assim como com novos integrantes da equipe, para que a entendam e tenham uma visão clara a seu respeito, de maneira que todo o trabalho do grupo esteja voltado para o mesmo foco.

- Recrutamento e Seleção: a Filosofia da Biblioteca necessita ser esclarecida para os novos colaboradores, no momento da seleção. Isso permite avaliar as habilidades técnicas dos entrevistados, suas expectativas quanto ao negócio, missão, princípios da BU e também facilita o processo de adesão e integração dos novos selecionados.

- Apresentação da Biblioteca e da IES: a apresentação da Biblioteca, isto é, dos seus serviços, produtos, programas, manuais de trabalho, instalações, políticas e procedimentos também se torna um instrumento de integração, tanto para os novos integrantes da equipe, quanto para os mais antigos, além de contribuir para a atualização e motivação do grupo. Todavia, sendo a Biblioteca Universitária um órgão da IES, deve-se trabalhar sempre em sintonia com os objetivos da Instituição. Sugere-se também, no mínimo, um programa institucional de apresentação anual para os novos integrantes da equipe da Biblioteca, com o intuito de ressaltar a missão, visão, princípios, finalidades, objetivos, metas e instalações da IES, o 
que propiciará, de certa forma, a integração dos colaboradores da BU com os outros colaboradores da instituição. Estes programas de apresentação, porém, precisam ser dinâmicos, de maneira que atraiam a atenção dos integrantes e, ao mesmo tempo, motiveos, não devendo ser impostos como uma obrigação a cumprir, de forma burocrática e rotineira.

- Programas de Treinamento, Capacitação e Desenvolvimento: este instrumento, além de promover a integração do indivíduo com suas atividades atuais, também auxilia no preparo do colaborador para assumir novas tarefas, na formação multidisciplinar e no desenvolvimento da equipe nos aspectos técnicos e humanos.

- Rituais Comemorativos e Associação dos Colaboradores: tais rituais como, por exemplo, comemorações de aniversário da própria BU e dos colaboradores, festas de Natal e Ano Novo, Páscoa ou até mesmo o Dia do Funcionário, entre outras, auxiliam na integração da equipe e facilitam o encontro dos colaboradores que trabalham em diferentes turnos. Também se torna interessante promover uma Associação dos Colaboradores, sendo eleita, anualmente, uma diretoria, a qual se encarrega de organizar os eventos (festas, jogos e lazer em geral) e arrecadar verbas dos associados. Portanto, de acordo com Arantes (1998), os novos padrões da sociedade moderna exigem das organizações a satisfação de diversos níveis de integração, tais como: da organização com a sociedade; dos indivíduos com a organização e com suas atividades; dos indivíduos com os grupos e destes entre si.

Motivação: a motivação pode ser trabalhada de várias formas em uma BU e, para isso, há alguns instrumentos que podem ser utilizados nas organizações . Abaixo, cada instrumento proposto por Arantes (1998) será analisado e adaptado ao contexto das Bibliotecas Universitárias.

- Remuneração: utilizada em muitas organizações para motivar os colaboradores, a remuneração engloba os salários, comissões, e benefícios tais como: planos de saúde, de alimentação, de educação, seguro de vida, moradia, entre outros. Embora a remuneração seja considerada como um dos principais instrumentos de motivação em uma organização, não consegue atender e satisfazer a todas as necessidades humanas, limitando-se às necessidades sociais, de auto-estima, auto-realização. Devido à BU estar vinculada a uma IES, o bibliotecário administrador dependerá muito da forma como a instituição utiliza esse instrumento, mas isso não significa que ele não possa negociar com a IES novas formas de utilizar a remuneração para motivar os seus colaboradores. Um exemplo poderia ser a distribuição de cotas de bolsas de estudo anuais para a equipe da BU, ou mesmo maiores descontos nas mensalidades dos cursos técnicos, de graduação ou pós-graduação.

- Meio Ambiente, Ergonomia e Prevenção de Acidentes: se houver esforços por parte da direção da BU para proporcionar maior qualidade de vida e segurança aos seus colaboradores, já se está contribuindo para a motivação da equipe. Esses esforços podem ser entendidos como: fornecimento de equipamentos ergonômicos para os computadores, mobiliários ergonômicos, climatização, iluminação adequada, equipamentos de proteção contra poeira, fungos, dedetizações periódicas etc.

- Assistência Social: várias organizações oferecem a seus colaboradores orientações sociais e psicológicas, complementando os programas educacionais da empresa. No caso das BUs, o bibliotecário administrador pode desenvolver programas de apoio aos colaboradores por meio de convênios com os próprios cursos de graduação, pós-graduação, técnicos e de extensão, contando com o auxílio de voluntários dos cursos de Serviço Social, Psicologia, Direito, entre outros.

- Inovação: "este instrumento incentiva os colaboradores a desenvolverem e aplicarem idéias novas capazes de trazer contribuições significativas aos resultados empresariais e atender às necessidades humanas 'superiores' dos colaboradores." (ARANTES, 1998, p. 378). Em uma BU, a inovação pode ser estimulada, por exemplo, com a implementação de um mural interno de sugestões, as quais podem ser analisadas e votadas por toda a equipe, sendo as aceitas premiadas de alguma forma.

Desse modo, os bibliotecários administradores precisam utilizar diferentes tipos de instrumentos de motivação para satisfazerem as diversas necessidades humanas: econômicas, fisiológicas, de segurança, sociais, de auto-estima e de auto-realização.

Ativação: para Arantes (1998, p.381), "os esforços de ativação nas empresas são baseados na 
relação entre pessoas e dependem fundamentalmente da capacidade de umas em influenciar o comportamento de outras para a realização das atividades requeridas à consecução dos objetivos empresariais." Esse componente do Subsistema Humano-Comportamental pode utilizar-se de diversos instrumentos para influenciar o comportamento dos indivíduos, de maneira que seus papéis e responsabilidades sejam assumidos de forma proativa, em relação aos objetivos organizacionais. $\bigcirc$ autor citado propõe alguns instrumentos de ativação para serem utilizados nas organizações, tais como:

- Filosofia e Visão de Futuro: estes dois instrumentos auxiliam nos esforços de ativação das pessoas, uma vez que estabelecem o papel que a organização desempenha na sociedade, seu modo de agir, a forma como pensa, o seu crescimento e a sua continuidade. Isso funciona como um estímulo para a mobilização das pessoas, já que sabem por que a organização existe, o que faz, no que acredita e qual é a sua visão de futuro.

- Estilo Gerencial: segundo Arantes (1998, p. 382), "a forma pela qual as relações de influência acontecem na empresa é um importante instrumento para ativar as pessoas a assumir seus papéis e responsabilidades e contribuir efetivamente pra os resultados empresariais." Todas as funções administrativas devem ser orientadas uniformemente pelo estilo gerencial adotado, para que haja um padrão de comportamento do diretor e, conseqüentemente, coerência no processo gerencial. Dessa forma, o estilo gerencial pode ser considerado um instrumento de auxilio ao bibliotecário administrador, porque ajuda na promoção da integração, motivação e ativação das pessoas para assumirem papéis e responsabilidades em relação aos resultados pretendidos.

- Comunicação: para que os integrantes de uma $\mathrm{BU}$ assumam seus papéis e responsabilidades, tornase necessária a existência de um eficiente processo de comunicação. Não basta apenas informar os papéis e responsabilidades da cada um, é preciso fazer com que todos compreendam e aceitem efetivamente seus papéis e responsabilidades. Contudo deve-se tomar cuidado na aplicação desses instrumentos de ativação, para que, ao invés de serem utilizados para ativarem as pessoas a assumirem seus papéis e responsabilidades de forma proativa, não acabem tornando-se instrumentos de desestímulo e "desativação".
Percebe -se, portanto, que o componente humano-comportamental é, de fato, um dos aspectos mais complexos de uma administração, já que as pessoas possuem expectativas, necessidades (econômicas, fisiológicas, de segurança, sociais, de auto-estima e de auto-realização), objetivos, sonhos, crenças e valores diferentes umas das outras. Nesse sentido, não se pode simplesmente considerá-las como um tipo de recurso de que a BU dispõe para alcançar seus objetivos, e sim, como o seu principal componente, o que exige muita atenção, dedicação e esforço do bibliotecário administrador, a fim de "[...] criar o ambiente e as oportunidades capazes de fazer com que as pessoas executem as atividades em direção aos resultados empresariais e, ao mesmo tempo, estejam satisfazendo suas necessidades e motivos, ou seja, conseguir a compatibilização entre os objetivos empresariais e os individuais." (Arantes, 1998, p.97).

\section{Subsistema Ambiental}

A questão ambiental ultrapassou o parcialismo e passou a ser uma preocupação universal, perpassando todos os campos do conhecimento. A compreensão, conscientização e a própria ação em prol do meio ambiente dependem efetivamente da concentração de esforços, isto é, do engajamento e da "parceria" de todos os campos do conhecimento.

Nesse contexto, surgem as universidades, as quais podem ser consideradas como um dos meios para se atingir o saber e a sensibilização ambiental, visto que:

[...] desempenham um papel fundamental nesses processos de transformação do conhecimento vinculados à construção de uma racionalidade ambiental por sua responsabilidade social na formação de novos saberes e novos profissionais com uma consciência crítica e uma capacidade para contribuir com eficácia na resolução de problemas socioambientais cada vez mais complexos. (Leff, 1995, p. 19).

Por outro lado, para que a Universidade cumpra seu papel, ou seja, contribua com a resolução da problemática ambiental, precisa contar com todos os seus órgãos de apoio, incluindo-se a Biblioteca. Sendo 
assim, a BU também possui sua parcela de responsabilidade ambiental, na qual, conseqüentemente, inserem-se os bibliotecários.

Nesse sentido, a problemática ambiental e a responsabilidade dos profissionais da informação em relação ao meio ambiente, vêm ganhando espaço e sendo debatida com maior ênfase no âmbito biblioteconômico, não só por meio das estruturas curriculares dos Cursos de Biblioteconomia e das publicações periódicas (impressas/on-line) da área, mas também em jornadas, congressos, simpósios e painéis, como ocorreu na XV Jornada Sul-Rio-Grandense de Biblioteconomia e Documentação, cujo tema central foi: "Meio ambiente: a dimensão da informação". A afirmação abaixo foi proferida pelos organizadores desse evento:

\footnotetext{
Os profissionais da informação, neste início de milênio, devem assumir a sua parcela de responsabilidade no processo de formação do conhecimento para a tomada de decisões na área ambiental. Faz-se necessário, uma profunda reflexão sobre o método de transferência da informação, desde sua geração, organização, recuperação e uso, visando à superação das dificuldades existentes. (Jornada..., 2001).
}

Esse engajamento da Biblioteconomia com a questão ambiental propagouse e ganhou forças, principalmente, depois da Conferência das Nações Unidas sobre Meio Ambiente e Desenvolvimento, celebrada no Rio de Janeiro, de 3 a 14 de junho de 1992, em que foi aprovada a Agenda $21^{8}$, que dedicou o capítulo 40 (Informação para a Tomada de Decisões) para tratar da importância da informação no desenvolvimento sustentável. No capítulo 40 da Agenda 21 , percebe-se o quão importante e fundamental é a participação do profissional bibliotecário no gerenciamento, disseminação, recuperação e democratização da informação ambiental para a comunidade em geral, e, no caso dos profissionais atuantes em Bibliotecas Universitárias, para a comunidade acadêmica, uma vez que:

[...] no desenvolvimento sustentável, cada pessoa é usuário de informação, considerada em sentido amplo, o que inclui dados, informações, experiências e conhecimentos adequadamente apresentados. A necessidade de informação surge em todos os níveis, desde o de tomada de decisões superiores, nos planos nacional e internacional, ao comunitário e individual. (Conferência..., 2001, p. 575).

Para iniciar esse processo de engajamento e contribuição com a resolução dos problemas ambientais, as BUs podem, inicialmente, começar a adotar medidas ambientalistas pequenas, mas que, no contexto acadêmico, acabam por auxiliar na sensibilização, conscientização, responsabilidade e qualidade ambiental.

O Subsistema Ambiental tem a função de definir as ações ambientalistas da BU. Por estar vinculada a uma IES, a BU deve seguir e ir ao encontro da sua política ambiental. Todavia, se a IES não possuir uma política ambiental, a BU pode criar sua própria política para nortear suas ações ambientais.

O Subsistema Ambiental proposto no presente estudo, portanto, baseia-se na ABNT NBR ISO 14001 (1996) e ABNT NBR ISO 14004 (1996), e será composto pelos seguintes componentes: política ambiental, plano de ação, implementação, medição e avaliação, análise crítica e melhoria contínua.

Segundo a ABNT NBR ISO 14004 (1996, p.6), política ambiental significa a "[...] declaração da organização, expondo suas intenções e princípios em relação ao seu desempenho ambiental global, que provê uma estrutura para a ação e definição de seus objetivos e metas ambientais." Essa mesma norma recomenda a utilização de princípios orientadores ${ }^{9}$ para

\footnotetext{
8 "A Agenda 21 está voltada para os problemas prementes de hoje e tem o objetivo, ainda, de preparar o mundo para os desafios do próximo século. Reflete um consenso mundial e um compromisso político no nível mais alto no que diz respeito a desenvolvimento e cooperação ambiental. $\bigcirc$ êxito de sua execução é responsabilidade, antes de mais nada, dos Governos. [...] A Agenda 21 é um programa dinâmico. Ela será levada a cabo pelos diversos atores segundo as diferentes situações, capacidades e prioridades dos países e regiões e com plena observância de todos os princípios contidos na Declaração do Rio sobre Meio Ambiente e Desenvolvimento." (CONFERÊNCIA DAS NAÇÕES UNIDAS SOBRE MEIO AMBIENTE E DESENVOLVIMENTO, 2001, p. 9-10).

9 "Princípios orientadores: são declarações formais com base nas quais uma política pode ser definida e que servem de base para ações a serem adotadas." (ABNT NBR ISO 14004, 1996, p. 28).
} 
auxiliar na definição da amplitude do comprometimento com o meio ambiente, proporcionando um conjunto de valores comuns, ou seja, esses princípios orientadores podem servir de base para o desenvolvimento da política ambiental da organização. Além disso, também recomenda considerar os seguintes itens na elaboração de uma política ambiental:

[...] - missão, visão, valores essenciais e crenças da organização; - requisitos das partes interessadas e a comunicação com elas; melhoria contínua; - prevenção de polvição; coordenação com outras políticas organizacionais (tais como qualidade, saúde ocupacional e segurança no trabalho); condições locais ou regionais específicas; conformidade com os regulamentos, leis e outros critérios ambientais pertinentes subscritos pela organização. (ABNT NBR ISO 14004, 1996, p.9).

Para que a organização cumpra sua política ambiental, a norma ABNT NBR ISO 14004 (1996) recomenda a formulação de um plano. Desse modo, baseando-se nessa norma, sugere-se neste Subsistema a utilização dos seguintes elementos para comporem o plano de ação da BU:
- Identificação dos aspectos e dos impactos ambientais significativos, associados às atividades, produtos e serviços de uma BU: para identificar os aspectos ambientais e a avaliação de impactos ambientais associados, a ABNT NBR ISO 14004 (1996) sugere quatro etapas para realizar este processo, que são:

Etapa 1 - Selecionar um processo, atividade, produto ou serviço.

Etapa 2 - Identificar o maior número de aspectos ambientais dessa atividade, produto ou serviço selecionado.

Etapa 3 - Identificar o maior número de impactos ambientais reais e potenciais, positivos e negativos, associados a cada aspecto ambiental identificado.

Etapa 4 - Avaliação da importância dos impactos.

Para auxiliar a avaliação da importância dos impactos ambientais, sugere-se uma classificação quanto à severidade do impacto, conforme o quadro 1 .

Também se sugere uma classificação quanto à freqüência com que o impacto poderá ocorrer. O quadro 2 apresenta a classificação sugerida.

Quadro 1. Classificação de severidade do impacto ambiental.

Fonte: Adaptação da classificação de severidade utilizada pela empresa Bunge Alimentos.

\begin{tabular}{|l|l|}
\hline $\begin{array}{l}\text { Baixa } \\
S=1\end{array}$ & $\begin{array}{l}\text { - A percepção da falha é possível por qualquer indivíduo. } \\
\text { - Não ocasiona nenhum tipo de necessidade de tratamento hospitalar. }\end{array}$ \\
\hline $\begin{array}{l}\text { Moderada } \\
S=2\end{array}$ & $\begin{array}{l}\text { - A percepção da falha é possível por meio de profissionais qualificados. } \\
\text { - Ferimentos em pessoas com necessidade de tratamento hospitalar. }\end{array}$ \\
\hline $\begin{array}{l}C \text { rítica } \\
S=3\end{array}$ & $\begin{array}{l}\text { - A falha ocorre sem aviso prévio. } \\
\text { - Envolve morte ou invalidez de pessoas da empresa. }\end{array}$ \\
\hline $\begin{array}{l}\text { Catastrófica } \\
S=4\end{array}$ & $\begin{array}{l}\text { - A falha ocorre sem aviso prévio. } \\
\text { - Envolve morte ou invalidez permanente de pessoas da empresa e/ou externas. }\end{array}$ \\
\hline
\end{tabular}

Quadro 2. Classificação da freqüência com que o impacto ambiental poderá ocorrer.

Fonte: Adaptação da classificação de severidade utilizada pela empresa Bunge Alimentos.

\begin{tabular}{|l|l|}
\hline Freqüente $\mathrm{F}=1$ & Possível de se observar pelo menos um evento a cada dia. \\
\hline Provável $\mathrm{F}=2$ & Possível de se observar pelo menos um evento a cada mês. \\
\hline Improvável $\mathrm{F}=3$ & Possível de se observar pelo menos um evento a cada ano. \\
\hline Remota $\mathrm{F}=4$ & Possível de se observar pelo menos um evento a cada cinco anos. \\
\hline Extremamente Remota $\mathrm{F}=5$ & Possível de se observar pelo menos um evento a cada 10 anos. \\
\hline
\end{tabular}


- Objetivos e Metas Ambientais: para atender à política ambiental da BU é necessário estabelecer os objetivos que se pretende atingir. Todavia, para que esses objetivos se tornem aplicáveis, basta quantificálos por meio de metas.

- Procedimentos e Métodos: após a definição dos objetivos e das metas, é preciso estabelecer a maneira como serão atingidos, ou seja, descrever os procedimentos e métodos a serem utilizados pela BU para atingir seus objetivos ambientais.

- Responsáveis: indicar sempre uma pessoa da equipe, ou mesmo um pequeno grupo, para se responsabilizar pelo cumprimento dos objetivos e metas ambientais estabelecidos.

- Prazo: é necessário estabelecer um prazo, dentro do qual os objetivos e as metas ambientais deverão ser atingidos.

Após o desenvolvimento do plano, passa-se para a etapa de implementação. Para isso, o bibliotecário administrador precisa capacitar sua equipe (treinamento e conscientização) e alocar os recursos necessários (físicos, financeiros) para atingir os objetivos de maneira eficaz.

De acordo com a ABNT NBR ISO 14004 (1996), após a implementação do plano, é fundamental medir e avaliar o desempenho ambiental por meio de indicadores, para assegurar que as ações propostas estejam de acordo com os objetivos e metas ambientais traçados. Esse monitoramento serve para identificar as ações que foram executadas com êxito e as que necessitam de ação corretiva e melhoria.

No entanto, além de estabelecer a política ambiental da BU, desenvolver o plano de ação, implementar, medir e avaliar seu desempenho, é de fundamental importância que ocorra também o aperfeiçoamento das ações ambientais, a análise crítica da direção da BU com relação a tais ações, isto é, comparar os resultados obtidos após a implementação do plano de ação com os objetivos e metas traçados anteriormente, analisar a eficácia das ações implementadas e se os resultados obtidos estão de acordo com a política ambiental e a melhoria contínua.

A ABNT NBR ISO 14004 (1996) recomenda alguns critérios a serem observados no processo de melhoria contínua, tais como:
- comparar os resultados com os objetivos e metas;

- determinar a causa ou as causas básicas de não conformidades ou deficiências;

- desenvolver e implementar plano(s) de ações corretivas e preventivas para abordar a(s) causa(s) básica(s);

- verificar a eficácia das ações corretivas e preventivas.

Portanto, para que a responsabilidade ambiental da Biblioteca Universitária possa ser cumprida, caberá ao bibliotecário administrador utilizar, da melhor maneira, os instrumentos que o Subsistema Ambiental oferece.

\section{CONCLUSÕES}

O SGBU mostrou-se aplicável, uma vez que foi implementado, em sua totalidade, na BU selecionada pela autora, comprovando a viabilidade prática. Dessa forma, verificou-se que o modelo de Sistema de Gestão proposto constitui-se em um efetivo instrumento de suporte à ação do profissional bibliotecário, o que confirma a hipótese de investigação da pesquisa, visto que se abordaram questões relevantes para 0 gerenciamento de uma BU.

O SGBU mostrou-se útil, prático e apresentou como pontos fortes os seguintes aspectos:

- permite ao bibliotecário administrador ser o agente desenvolvedor de seu próprio método de trabalho, de acordo com sua realidade;

- não apresenta uma estrutura rígida, e pode ser utilizado por qualquer BU, desde que seja entendido como uma base conceitual associada à práxis cotidiana e devidamente adaptada às diferentes realidades;

- proporciona maior qualidade aos serviços prestados pela BU;

- orienta as decisões e ações dos diferentes colaboradores (diretor, supervisores, auxiliares) para os resultados almejados, isto é, oferece instrumentos para o desenvolvimento de padrões uniformes que servem para orientar 
a tomada de decisão, assegurando o entendimento uniforme de toda a equipe;

- auxilia o bibliotecário administrador a desempenhar, com eficácia, as funções administrativas, porque trabalha com um conjunto de métodos, técnicas e subsídios teórico-práticos relevantes para a gestão de BU;

- padroniza os processos operacionais;

- propõe ações para a melhoria da qualidade de vida dos colaboradores, bem como ações voltadas para a segurança do trabalho;

- permite a participação efetiva de todos os colaboradores na sua consecução, promovendo a integração, motivação e ativação da equipe;

- oportuniza instrumentos de auxílio para desenvolver a educação continuada, o desenvolvimento e a capacitação dos colaboradores;

- trabalha a responsabilidade ambiental do profissional da informação e, conseqüentemente, dos colaboradores e da comunidade acadêmica.

\section{REFERÊNCIAS}

ALMEIDA, M.I.R. Manual de planejamento estratégico: desenvolvimento de um plano estratégico com a utilização de planilhas Excel. São Paulo: Atlas, 2001. 156p.

ARANTES, N. Sistemas de gestão empresarial: conceitos permanentes na administração de empresas válidas. 2.ed. São Paulo: Atlas, 1998. 439p.

ARAÚJO, L.C.G. Organização, sistemas e métodos e as modernas ferramentas de gestão organizacional: arquitetura organizacional, benchmarking, empowerment, gestão pela qualidade total, reengenharia. São Paulo: Atlas, 2001. 311 p.

ASSOCIAÇÃO BRASILEIRA DE NORMAS TÉCNICAS - ABNT. NBR ISO 14001 : sistemas de gestão ambiental: especificação e diretrizes para uso. Rio de Janeiro, out. 1996. 14p.

ASSOCIAÇÃO BRASILEIRA DE NORMAS TÉCNICAS - ABNT. NBR ISO 14004: sistemas de gestão ambiental: diretrizes gerais
Embora tenham-se abordado ações relevantes para uma gestão de BU, um Sistema de Gestão é algo complexo, visto que envolve um conjunto de funções, técnicas e instrumentos administrativos, tornando-se difícil abarcar sua totalidade. Assim, o sistema proposto também apresentou algumas limitações:

- o sistema prevê pouca interação da BU com o ambiente institucional, sendo necessária maior exploração da relação BU versus IES e uma forma mais clara para a promoção dessa integração;

- ainda que se tenha reforçado a importância da abordagem sistêmica e os requisitos de integração dos subsistemas, o SGBU não prevê uma forma de apontar as relações de cada subsistema com os demais, dificultando a visão geral destas relações na hora da implementação.

Acredita-se, portanto, que esta pesquisa apresentou ações relevantes para o gerenciamento de BU, contribuindo não apenas para um melhor entendimento a respeito da importância e necessidade do preparo gerencial do bibliotecário administrador, mas também, sobretudo, para a melhoria contínua das BU.
- pouca ênfase à Tl;

sobre princípios, sistemas e técnicas de apoio. Rio de Janeiro, out. 1996. 32p.

BARBALHO, C.R.S.; BERAQUET, V.S.M. Planejamento estratégico para unidades de informação. São Paulo: Polis, 1995. 69p. (Coleção Palavra-Chave, 5).

CHIAVENATO, I. Administração nos novos tempos. Rio de Janeiro: Campus, 1999. 710p.

CONFERÊNCIA DAS NAÇÕES UNIDAS SOBRE MEIO AMBIENTE E DESENVOLVIMENTO, 1992, Rio de Janeiro. Agenda 21. 3.ed. Brasília: Senado Federal, 2001. 598p.

CÔRTE, A.R.; ALMEIDA, I.M. (Orgs.). Avaliação de softwares para bibliotecas. São Paulo: Polis/APB, 2000. 108p.

DAVENPORT, T.H. Missão crítica: obtendo vantagem competitiva com os sistemas de gestão empresarial. Porto Alegre: Bookman, 2002. 293p. 
DELORS, J. et al. Educação: um tesouro a descobrir: relatório para a UNESCO da Comissão Internacional sobre Educação para o Século XXI. 2. ed. São Paulo: Cortez; Brasília: UNESCO, 1999. 288p.

DIEKANIAK, G.V. Análise do software Bibliotech sob a ótica da Biblioteconomia. 2003. 263f. Dissertação (mestrado em engenharia de produção) - Universidade Federal de Santa Maria, Santa Maria, 2003.

FUNDAÇÃO PARA O PRÊMIO NACIONAL DA QUALIDADE $F P N Q$ (Ed.). Critérios de excelência: o estado da arte da gestão para a excelência do desempenho. São Paulo: FPNQ, 2002

JORNADA SUL-RIO-GRANDENSE DE BIBLIOTECONOMIA E DOCUMENTAÇÃO, 15., 2001, Porto Alegre. Meio ambiente: a dimensão da informação - impresso. Porto Alegre: Associação Riograndense de Bibliotecários, 2001. 1 folder.
LEFF, E. As universidades e a formação ambiental na América Latina. Cadernos de Desenvolvimento e Meio Ambiente, Curitiba, n.2, p.11-20, 1995.

OLIVEIRA, D.P.R. Planejamento estratégico: conceitos, metodologias e práticas. 17. ed. rev. ampl. São Paulo: Atlas, 2002. 337 p.

PASSOS, E. O futuro da biblioteca jurídica. Disponível em: < http:/ /www.gidjir.com.br/artigo2.htm>. Acesso em: 14 jul. 2005.

STONER, J.A.F.; FREEMAN, R.E. Administração. 5.ed. Rio de Janeiro: LTC, 1999. 533p.

VALADARES, M.C.B. Planejamento estratégico empresarial: foco em clientes e pessoas: técnicas para a sua elaboração passo a passo. Rio de Janeiro: Qualitymark, 2002. 118p. 